\title{
Composição Química do Capim-Elefante cv. Roxo Cortado em Diferentes Alturas1
}

\author{
Estácio Alves dos Santos², Divan Soares da Silva ${ }^{3}$, José Leite de Queiroz Filho ${ }^{3}$
}

\begin{abstract}
RESUMO - O objetivo deste trabalho foi verificar o efeito dos cortes efetuados a 0,15, 30 e 45 cm sobre a composição química do capim-elefante (Pennisetum purpureum, Schum.) cv. Roxo, em épocas seca e chuvosa. As amostras foram obtidas de uma área útil de $8,4 \mathrm{~m}^{2}$ de cada parcela. Após o corte de uniformização, efetuaram-se dois cortes no período seco, em intervalos de 90 dias, e três no período chuvoso, em intervalos de 60 dias. De cada parcela foi tomada uma amostra de 3 a 5 perfilhos, desidratada em estufa e triturada para analises laboratoriais. Foram avaliados os percentuais de matéria seca (MS), proteína bruta (PB), fibra em detergente neutro (FDN), fibra em detergente ácido (FDA), celulose (CEL), hemicelulose (HCEL), lignina (LIG) e cinzas. As alturas de corte não influenciaram a composição química da forrageira, nem houve interação com as épocas. Com exceção de hemicelulose e cinzas, os cortes na época seca mostraram resultados superiores à chuvosa. As médias nas duas épocas foram 19,70 e 17,44\% para MS; 7,74 e 7,25\% para PB; 76,41 e 71,13\% para FDN; 42,75 e 41,02\% para FDA; 31,44 e 30,43\% para CEL; 30,66 e 30,28\% para HCEL; 9,25 e 7,83\% para LIG; e 1,97 e $3,38 \%$ para cinzas, nos períodos seco e chuvoso, respectivamente.
\end{abstract}

Palavras-chave: celulose, estações, fibra, lignina, Pennisetum purpureum, proteína

\section{Chemical Composition of Elephant Grass var. Roxo Cut at Different Heights}

\begin{abstract}
This work was carried out to evaluate the cutting effect at 0,15, 30 and $45 \mathrm{~cm}$ height, on the chemical composition of elephant grass (Pennisetum purpureum, Schum.) cv. Roxo in dry and rainy seasons. The samples were obtained from an useful area of $8,4 \mathrm{~m}^{2}$ from each parcel. After the uniformity cut two cuts in dry season with 90 days interval, and three cuts in rainy seasons with 60 days interval. A sample of 3 or 5 tillers was taken from each parcel and they were dehydrated in air forced stove and ground for laboratorial analysis. The percentages of dry matter (DM), crude protein (CP), neutral detergent fiber (NDF), acid detergent fiber (ADF), cellulose (CEL), hemicellulose (HCEL), lignin (LIG), and ashes were evaluated. The cutting heights did not influence the chemical composition of the grass, neither there was interaction with the seasons. Except for hemicellulose and ashes, the cut made in the dry season showed superior results than in the rainy season. The averages for the two periods were 19.70 and $17.44 \%$ for MS, 7.74 and $7.25 \%$ for CP, 76.41 and $71.13 \%$ for NDF, 42.75 and $41.02 \%$ for ADF, 31.44 and $30.43 \%$ for CEL, 30.66 and $30.28 \%$ for HCEL, 9.25 and $7.83 \%$ for LIG, and 1.97 and $3.38 \%$ for ashes, in dry and rainy seasons, respectively.
\end{abstract}

Key Words: cellulose, fiber, lignin, Pennisetum purpureum, protein, seasons

\section{Introdução}

Os aspectos climáticos, associados à localização geográfica e à fertilidade do solo, constituem-se os elementos que mais dificultam a introdução de forrageiras exóticas. A maioria das áreas agrícolas do Nordeste apresenta alta incidência de luminosidade e temperatura favoráveis à forragicultura, entretanto, o longo período de estiagem limita a expansão de folhas e colmos pelo processamento fotossintético, além de reduzir a disponibilidade e o fluxo de nutrientes do solo para as folhas, podendo, possivelmente em função disso, reduzir a qualidade da forragem nesse período.

Embora a composição química não se defina como único critério para se determinar a qualidade do alimento, por meio do seu conhecimento e dos resultados de pesquisa que se dispõe em literatura pertinente, pode-se firmar algumas hipóteses sobre o valor nutricional das forrageiras

É de consenso comum entre os pesquisadores que os constituintes mais desejáveis em uma forragem reduzem com a idade da planta e varia de acordo com a parte da planta amostrada. Isso permite inferir que a produção por área, verificada em intervalos de corte mais prolongados, nem sempre significa melhor aproveitamento da forrageira, mas o tipo de manejo aplicado à campineira pode vir a melhorar ou piorar a sua qualidade.

Manter a forragem no campo por muito tempo significa perda inevitável na qualidade do material.

\footnotetext{
1 Parte da Dissertação de Mestrado do primeiro autor. Trabalho financiado pela CAPES.

2 Pós-Graduando em Produção Animal, UNESP - Jaboticabal, SP - Rod. Paulo D. Castellane, Km 5, CEP 14870-000.E.mail:estacio@fcav.unesp.br 3 Professor do DZ/CCA/UFPB, Campus III, Areia-PB. CEP 58.397-000.
} 
Segundo ANDRADE e GOMIDE (1971), o intervalo de corte é fator importante para a variação da composição química da forragem. Esses autores verificaram redução de mais de $50 \%$ no teor de proteína bruta, entretanto com elevação pouco significativa no teor de carboidratos solúveis no capimelefante cortado em intervalos de 56 e 84 dias. GONÇALVES e COSTA (1997), trabalhando com a cultivar Cameroon, também cortada aos 56 e 84 dias, observaram variação menor no teor de proteína bruta, com médias em torno de 9,36 e 7,13\%, respectivamente.

Trabalhos de Maraschin e Nabinger, citados por JACQUES (1994) mostraram teores de proteína variando de 5,38 a 12,81 em várias cultivares de capim-elefante estudadas. Segundo esses autores, as estações do ano têm influência não somente na produção de massa verde por área, mas também na composição química e bromatológica.

Embora WERNER et al. (1966) tenham obtido teores protéicos bastante altos $(19,97$ e 18,17\%, com cortes rentes ao solo e 15-20 cm, respectivamente), vários outros trabalhos mostram que o teor de proteína bruta do capim-elefante comumente varia de 3,4 a 12,93, de acordo com a cultivar e a idade do corte (SILVEIRA et al., 1974; GONÇALEZ, 1985; AVEIRO et al., 1991; GONÇALVES e COSTA, 1991 e SANTOS, 1994).

Nos componentes da fração fibrosa, enquanto a variação do teor de celulose obedece à curva do intervalo de corte, a lignina parece que nem sempre segue esta mesma tendência (GENNARI e MATOS, 1977), indicando que há outros fatores responsáveis pelo acúmulo de lignina nos tecidos vegetais, como a época de corte, a umidade do solo, a temperatura e a luminosidade (BALL, et al. 1996; SANTOS, 1994; e PLUT e WERNER, 1967).

Pesquisadores concordam haver relação da idade e altura do corte com os percentuais de carboidratos estruturais e lignina nas plantas (NASCIMENTO e PINHEIRO, 1975), mas também o ambiente pode interferir. VAN SOEST (1964) mostrou que a temperatura tem forte interferência sobre a fração de lignina em uma mesma forrageira de mesma idade.

Os animais herbívoros necessitam de quantidade de fibra efetiva na sua dieta, mas vale salientar que, à medida que a FDA indigestível se eleva, outros componentes do grupo de NDT são reduzidos no alimento. Desse modo, mesmo em condições específicas, em se tratando de produção animal, a capineira necessita ser manejada de modo a oferecer uma forragem com melhor composição química possível.
O objetivo do presente trabalho foi estudar o efeito de das alturas dos cortes sobre a composição química do capim-elefante, cv. Roxo, em períodos seco e chuvoso, no Brejo Paraibano.

\section{Material e Métodos}

O experimento foi desenvolvido na área de forragicultura do Departamento de Zootecnia do CCA-UFPB, Campus III, Areia-PB. O clima é do tipo AS quente e úmido, com chuvas de outonoinverno e precipitação, em torno de $1400 \mathrm{~mm}$ anuais. A temperatura média anual oscila entre 23 e $24^{\circ} \mathrm{C}$ e o soloé do tipo podzólico vermelho-amarelo (BRASIL, 1973), com textura arenosa.

A região do Brejo Paraibano consiste de uma microregião geográfica com características climáticas peculiares, constituindo-se em uma área de microclima, o que acentua a relevância à observação dos dados meteorológicos; além disso, a distribuição pluviométrica durante o intervalo no qual se conduziu o experimento tornou este um período atípico, com chuvas distribuídas durante todo o ano, mesmo em período de típica estiagem (SANTOS, 2001).

O plantio foi feito em parcelas medindo $15 \mathrm{~m}^{2}$, em covas com espaçamento de $70 \times 80 \mathrm{~cm}$, utilizando segmentos de colmo medindo cerca de $30 \mathrm{~cm} \mathrm{e}$ contendo três gemas. Por ocasião do plantio, foram aplicados em cobertura $30 \mathrm{~kg} / \mathrm{ha}$ de $\mathrm{P}_{2} \mathrm{O}_{5}, 20 \mathrm{~kg} / \mathrm{ha}$ de $\mathrm{K}_{2} \mathrm{O}$. Dois anos após o plantio, os tratos préexperimentais em toda a capineira consistiram em: um corte rente ao solo, correção do $\mathrm{pH}$ do solo com aplicação de 2,8 t/ha de calcário e adubação em cobertura aplicando $30 \mathrm{~kg}$ de $\mathrm{P}_{2} \mathrm{O}_{5}, 20 \mathrm{~kg}$ de $\mathrm{K}_{2} \mathrm{O}$ e $50 \mathrm{~kg}$ de $\mathrm{N}$ por hectare na forma de superfosfato triplo, cloreto de potássio e sulfato de amônia, respectivamente. Em 09/96, fez-se um corte de uniformização das parcelas nas alturas de $0,15,30$ e $45 \mathrm{~cm}$ e aplicação de $50 \mathrm{~kg} / \mathrm{ha}$ de $\mathrm{N}$ pelo mesmo sistema, iniciando-se então o período experimental. As aplicações de adubos seguiram recomendações feitas com base em análise do solo (SANTOS, 2001).

Foram realizados seis cortes durante o período experimental. O primeiro foi realizado para uniformização das parcelas e outros cinco cortes, para coleta de dados, sendo dois em período de menor precipitação (julho a dezembro), a cada 90 dias, e três cortes em época chuvosa (janeiro a junho) a cada 60 dias. Os cortes foram feitos manualmente nas alturas de 0,15 , 30 e $45 \mathrm{~cm}$ da superfície do solo, numa área útil de $8,4 \mathrm{~m}^{2}$.

A cada corte da forrageira, foi retirada uma 
Rev. bras. zootec.

amostra de 3 a 5 perfilhos inteiros, cortados em pedaços de $3 \mathrm{a} 4 \mathrm{~cm}$, pesados e conduzidos ao laboratório e, após, colocados em estufa de ventilação forçada a $60^{\circ} \mathrm{C}$ durante 72 horas. As amostras foram moídas em moinho com peneiras de 40 mesh, acondicionadas em frascos de vidros e analisadas posteriormente.

A análise da matéria seca, proteína bruta (semi-micro), fibra em detergente neutro, fibra em detergente ácido, celulose, hemicelulose, lignina e cinzas foi feita no Laboratório de Nutrição Animal do Centro de Ciências Agrárias/UFPB, Areia, segundo as metodologias descritas por SILVA (1991).

O delineamento foi de blocos casualizados, em um esquema fatorial $4 \times 2$, sendo quatro alturas de corte $(0,15,30$ e $45 \mathrm{~cm})$ e duas épocas, seca e chuvas, com quatro repetições, conforme o seguinte modelo:

$$
Y_{i j k}=\mu+\alpha_{i}+E_{j}+\beta k+(\alpha E)_{i j}+e_{i j k},
$$

em que $Y_{i j k}$ é o valor relativo à parcela que recebeu o corte na altura i na época $\mathrm{j}$ e no bloco $\mathrm{k}$; $\mu$, a média geral; $\alpha_{\mathrm{i}}$, o efeito da i-ésima altura de corte; $\mathrm{E}_{\mathrm{j}}$, o efeito da j-ésima época; $\beta_{\mathrm{k}}$, o efeito do k-ésimo bloco; $\alpha x E$, o efeito da interação altura x época de corte; $\mathrm{e}_{\mathrm{ijk}}$, o erro aleatório associado a cada observação.

A análise de variância foi realizada pelo GLM Procedures (SAS, 1993) e as médias obtidas foram comparadas pelo teste Tukey a 5\% de significância.

\section{Resultados e Discussão}

Constam das Tabelas 1 e 2 as médias referentes à composição química do capim-elefante cv. Roxo, em função das diferentes alturas de corte. As análises de variância revelaram que não houve efeito da interação entre as épocas e as alturas de corte, nem com as alturas de corte entre si, para todas as variáveis estudadas. As médias dos teores de MS, PB, FDN e FDA foram 18,56; 7,50; 72,27; e 41,89\%, respectivamente.

Os teores médios de proteína bruta obtidos com a cultivar em estudo foram semelhante aos resultados de DESCHAMPS (1997), que trabalharam com a mesma cultivar em Santa Catarina. Por outro lado, estes resultados indicaram melhores características bromatológicas que as médias obtidas por GENNARI e MATTOS (1977), trabalhando com as variedades Cameron, Taiwan A-146 e Napier. Teores mais altos de proteína bruta, no entanto, foram encontrados com a variedade Taiwan-241cortada aos 42 dias em trabalho realizado por HARTHMANN et al. (1996).

Inferindo sobre a importância do teor de proteína bruta sobre os processos fisiológicos, VEIGA e CA-
Tabela 1 - Matéria seca (MS), proteína bruta (PB) fibra em detergente neutro (FDN) e fibra em detergente ácido (FDA) do capim-elefante cv. Roxo, em função da altura dos cortes, com base na matéria seca

Table 1 - Dry matter (DM), crude protein (CP), neutral detergent fiber (NDF) and acid detergent fiber (ADF) of the elephant grass var. Roxo, in function of cutting height, as dry matter basis

\begin{tabular}{lcccc}
\hline $\begin{array}{l}\text { Altura do corte (cm) } \\
\text { Cutting height }\end{array}$ & $\begin{array}{c}\text { MS } \\
(\%)\end{array}$ & $\begin{array}{c}\text { PB } \\
(\%)\end{array}$ & $\begin{array}{c}\text { FDN } \\
(\%)\end{array}$ & $\begin{array}{c}\text { FDA } \\
(\%)\end{array}$ \\
& $D M$ & $C P$ & $N D F$ & $A D F$ \\
\hline 0 & 17,89 & 7,27 & 71,89 & 42,26 \\
15 & 18,38 & 7,56 & 72,33 & 41,96 \\
30 & 18,47 & 7,60 & 72,75 & 41,80 \\
45 & 19,51 & 7,55 & 72,10 & 41,52 \\
Média & 18,56 & 7,50 & 72,27 & 41,89 \\
Mean & & & & \\
CV $(\%)$ & 6,70 & 6,30 & 1,41 & 4,27 \\
Significância & ns & ns & ns & ns
\end{tabular}

Significance

ns Não-significativo pelo teste Tukey a $5 \%$.

ns Not significant by Tukey test at $5 \%$.

MARÃO (1984) consideram que 7\% de PB é um nível crítico em uma forrageira; porém, segundo MINSON (1984), este seria o nível mínimo estimado de PB para que o alimento tenha adequada fermentação ruminal. Segundo Milford e Minson, citados por GONÇALVES e COSTA (1991), teores de proteína bruta inferiores a 7\% são limitantes à produção animal, devido a baixos consumos voluntários, menores coeficientes de digestibilidade e balanço negativo de nitrogênio. Pelas médias obtidas neste trabalho, infere-se que o teor médio de proteína bruta contido na matéria seca da forrageira em estudo foi superior aos limites críticos defendidos pelos autores supracitados. Em outros trabalhos realizados com a mesma cultivar e no mesmo microclima do Brejo Paraibano, realizando cortes rentes ao solo aos 40, 6080 e 100 dias, foram obtidos teores protéicos com médias em torno de 8,96\% (QUEIROZ FILHO et al., 1994; NASCIMENTO, 1997 e QUEIROZ FILHO et al., 1997).

As frações de FDN e FDA, que normalmente se elevam com o avançar da idade da planta, no capimelefante Roxo cortado aos 60 e 90 dias foram semelhantes aos percentuais encontrados por RODRIGUEZ et al. (1994), no capim Napier cortado aos 28 dias de idade, e por QUEIROZ FILHO et al. (1998), que obtiveram na cultivar Roxo teores médios de 71,8 e 41,6\% para FDN e FDA, respectivamente. Por outro lado, os valores destas variáveis neste ensaio também se mostraram superiores aos resultados de 
SANTOS et al.

Tabela 2 - Médias dos teores de celulose, hemicelulose, lignina e cinzas no capim-elefante cv Roxo, em função da altura dos cortes, com base na matéria seca

Table 2 - Averages of cellulose, hemicellulose, lignin and ashes in the elephant grass var. Roxo, in function of the the cutting heights, as dry matter basis

\begin{tabular}{|c|c|c|c|c|}
\hline $\begin{array}{l}\text { Altura do corte }(\mathrm{cm}) \\
\text { Cutting height }\end{array}$ & $\begin{array}{l}\text { Celulose }(\%) \\
\text { Cellulose }\end{array}$ & $\begin{array}{c}\text { Hemicelulose }(\%) \\
\text { Hemicellulose }\end{array}$ & $\begin{array}{l}\text { Lignina }(\%) \\
\text { Lignin }\end{array}$ & $\begin{array}{c}\text { Cinzas }(\%) \\
\text { Ashes }\end{array}$ \\
\hline 0 & 30,76 & 29,75 & 8,88 & 2,81 \\
\hline 15 & 31,17 & 30,37 & 8,26 & 2,65 \\
\hline 30 & 30,68 & 31,18 & 8,74 & 2,68 \\
\hline 45 & 31,15 & 31,58 & 8,28 & 2,54 \\
\hline Média & 30,94 & 30,72 & 8,54 & 2,68 \\
\hline \multicolumn{5}{|l|}{ Mean } \\
\hline $\mathrm{CV}(\%)$ & 4,05 & 6,57 & 11,58 & 8,95 \\
\hline $\begin{array}{l}\text { Significância } \\
\text { Significance }\end{array}$ & $\mathrm{ns}$ & $\mathrm{ns}$ & $\mathrm{ns}$ & $\mathrm{ns}$ \\
\hline
\end{tabular}

ns Não houve efeito significativo $(P>0,05)$ dos tratamentos pelo teste Tukey.

ns There was no significant effect of treatments $(P>.05)$ by Tukey test.

HARTHMANN et al. (1996) com a cultivar Taiwan-145.

$\mathrm{Na}$ Tabela 2 estão os percentuais de celulose, hemicelulose, lignina e cinzas da forrageira em estudo. De acordo com a análise de variância, não houve efeito significativo das alturas de corte sobre as medias obtidas para estas variáveis, nem foi significativa a interação entre os tratamentos. As plantas cortadas mais alto apresentaram menor fração de colmos que os cortes mais baixos (SANTOS et al., 2001), no entanto, estas hastes cresceram mais rígidas e lignificadas para garantir maior sustentação dos perfilhos aéreos. Fenômeno semelhante pode ser atribuído aos carboidratos estruturais durante o processo de maturidade das plantas. Os valores médios observados foram $30,94 \%$ para a celulose; $30,72 \%$ para a hemicelulose; $8,54 \%$ lignina e 2,68\% para cinzas.

Uma das vantagens da análise da fibra pelo método de Van Soest seria a possibilidade de separação da lignina das cadeias de carboidratos estruturais, impedindo que a mesma seja inclusa nos NDT, o que ocorre quando se utiliza o tradicional processo de extração da fibra bruta (SILVEIRA et al., 1974). Portanto, os teores de lignina e celulose obtidos confirmaram os achados por QUEIROZ FILHO et al. (1997), com a cultivar Roxo cortada rente ao solo em intervalos de 40, 60, 80 e 100 dias.

De acordo com a Tabela 3, as frações fibrosas, exceto a hemicelulose, na época seca, apresentaram índices superiores aos da época chuvosa. Esta diferença pode estar relacionada tanto com a menor proporção de lâmina foliar naquele período, como também ao maior intervalo de cortes (90 dias) na época seca (WILSON, 1994). O percentual de matéria seca da forragem, quando cortada no período de estiagem, foi superior $(\mathrm{P}<0,05)$ ao da época chuvosa, período em que as plantas retiveram na sua constituição maior quantidade de água.

Como mostra a Tabela 3, a lignina manteve-se com índices bastante altos em relação a outros trabalhos observados na literatura. Teores de 4,4 e 5,4\% foram observados por GENNARI e MATTOS (1977) em capim-elefante aos 63 e 84 dias, respectivamente, enquanto RODRIGUEZ et al. (1994) encontraram $4,44 \%$ e HARTHMANN et al. (1996), 3,75\%. A fração de lignina na época seca foi superior $(\mathrm{P}<0,05)$ à da época chuvosa; estes resultados certamente obedecem à ordem do maior intervalo de cortes, que possibilitou maior alongamento do caule, em detrimento da área foliar, o que também pode se constituir mecanismo das plantas, geralmente comum naquele período, para contenção das perdas de água. Resultados semelhantes foram encontrados por PLUT e WERNER (1967), estudando o efeito da época sobre o conteúdo de lignina do capim Napier.

A importância que se dá à presença da lignina na forragem está voltada não somente para a questão da sua digestibilidade quase nula, mas principalmente à sua ligação aos outros componentes da fibra. A lignina é um componente estrutural amorfo, que parece ter função "cimentante" nas ligações dos compostos da parede celular; aparece impregnada na celulose e hemicelulose formando um complexo lingnocelulósico indisponibilizando aqueles carboidratos à degradação pelos microrganismos.

Os resultados médios de FDN e FDA obtidos neste trabalho foram semelhantes aos obtidos por RODRIGUEZ et al. (1994a) e superiores aos de LAVEZZO et al. (1989), que obtiveram $66,89 \%$ de 
22 Rev. bras. zootec.

Tabela 3 - Composição química do capim-elefante cv. Roxo - médias dos cortes efetuados nas estações seca e chuvosa

Table 3 - Chemical composition of elephant grass, var. Roxo averages of cuttings at drought and rainy seasons

\begin{tabular}{|c|c|c|c|}
\hline \multirow{2}{*}{$\begin{array}{l}\text { Variáveis } \\
\text { Variables }\end{array}$} & \multicolumn{2}{|c|}{ Período } & \multirow{2}{*}{$\mathrm{CV}(\%)$} \\
\hline & $\begin{array}{c}\text { Seca }^{1} \\
\text { Dryperiod }\end{array}$ & $\begin{array}{c}\text { Chuva }^{2} \\
\text { Rainy period }\end{array}$ & \\
\hline Matéria seca (\%) & $19,70^{\mathrm{A}}$ & $17,44^{\mathrm{B}}$ & 6,70 \\
\hline $\begin{array}{l}\text { Dry matter } \\
\text { Proteína bruta }(\%)\end{array}$ & $7,74^{\mathrm{A}}$ & $7,25^{\mathrm{B}}$ & 6,29 \\
\hline $\begin{array}{l}\text { Crude protein } \\
\text { Fibra em detergente } \\
\text { neutro }(\%)\end{array}$ & $76,41^{\mathrm{A}}$ & $71,13^{\mathrm{B}}$ & 1,40 \\
\hline $\begin{array}{l}\text { Neutral detergent fiber } \\
\text { Fibra em detergente } \\
\text { ácido }(\%)\end{array}$ & $42,75^{\mathrm{A}}$ & $41,02^{\mathrm{B}}$ & 4,28 \\
\hline $\begin{array}{l}\text { Acid detergent fiber } \\
\text { Celulose }(\%) \\
\text { Cellulose }\end{array}$ & $31,44^{\mathrm{A}}$ & $30,43^{\text {B }}$ & 4,05 \\
\hline $\begin{array}{l}\text { Hemicelulose }(\%) \\
\text { Hemicellulose }\end{array}$ & $30,66^{\mathrm{A}}$ & $30,28^{\mathrm{A}}$ & 11,58 \\
\hline $\begin{array}{l}\text { Lignina }(\%) \\
\text { Lignin }\end{array}$ & $9,25^{\mathrm{A}}$ & $7,83^{\mathrm{B}}$ & 6,57 \\
\hline $\begin{array}{l}\text { Cinzas (\%) } \\
\text { Ashes }\end{array}$ & $1,97^{\mathrm{B}}$ & $3,38^{\mathrm{A}}$ & 8,95 \\
\hline $\begin{array}{l}\text { Médias nas linhas segu } \\
\text { teste Tukey (5\%). } \\
{ }^{1} \text { Médias de dois cortes. } \\
{ }^{2} \text { Médias de três cortes. } \\
{ }^{1} \text { Means of two cuts. } \\
{ }^{2} \text { Mean of three cuts. } \\
\text { Means, within a row, follon } \\
\text { test (5\%). }\end{array}$ & ed by the san & s do not differ & rem pelo \\
\hline
\end{tabular}

FDN e $35,38 \%$ de FDA, também trabalhando com capim-elefante; já a celulose, a hemicelulose e lignina foram superiores aos do trabalho supracitado.

\section{Conclusões}

As alturas dos cortes no capim-elefante cv. Roxo, quando efetuados nas idades do presente ensaio, não melhoraram a qualidade da forragem quanto à sua composição química.

Os cortes realizados no período de estiagem propiciaram maior acúmulo dos componentes da fração fibrosa na forragem.

Os cortes efetuados no período de menor precipitação e em intervalos de 90 dias proporcionaram maior formação de complexos lignocelulósicos, sem afetar o teor de hemicelulose na forragem.

\section{Referências Bibliográficas}

ANDRADE, I.F., GOMIDE, J.A. 1971. Curva de crescimento e valor nutritivo de capim-elefante (Pennisetum purpureum, Schum.) Taiwan A-146. R. Ceres, (18):431-47.

ARAÚJO FILHO, J.A., GADELHA, J.A., LEITE, E.R. et al. 1996. Consorciação do capim-elefante (Pennisetum purpureum, Schum) e da cunhã (Clitória ternatea $\mathrm{L}$.) sob quatro intervalos de corte. Past. Trop., 18(1):47-50.

AVEIRO, A.R., SIEWERDT, L., SILVEIRA JR., P. 1991. Capim-elefante: efeitos da irrigação e das adubações mineral e orgânica. I - Teor e produção total de matéria seca. R. Soc. Bras. Zootec., 20(4):239-247.

BALL, D.M., HOVELAND, C.S., LACEFILD, G.D. 1996. Southern forages, Atlanta, Georgia: PPI-EAR. 256 p.

BRASIL, Departamento Nacional de Obras Contra a Seca. 1973. Relatório Anual. Recife: DNOSCS. p.47-56.

DESCHAMPS, F.C. Perfil fenológico de três ecotipos de capimelefante (Pennisetum purpureum, Schum.). In: REUNIÃO ANUAL DA SOCIEDADE BRASILEIRA DE ZOOTECNIA, 34, Juiz de Fora, 1997. Anais... Juiz de Fora: SBZ, 1997, v.2, p.61-63.

GENNARI, S.M., MATOS, H.B. 1977. Influência da idade do estand sobre a produção, digestibilidade e composição de três variedades de capim-elefante (Pennisetum purpureum, Schum.). Bol. Ind. Anim., 34(2):253-62.

GONÇALEZ, D.A. 1985. Capim-elefante (Pennisetum purpureum, Schum.) cv. Roxo de Botucatu. Bol. Ind. Anim., 42(1):141-42.

GONÇALVES C.A., COSTA, L.C. 1991. Adubação orgânica, frequência de corte de capim-elefante (Pennisetum purpureum. Schum, cv. Cameroon) em Porto Velho, Rondônia. Lav. Arroz., 44(396):27-29.

GONÇALVES, C.A., COSTA, N.L. 1997. Curva de crescimento de capim-elefante cv. Cameroon nos Cerrados de Rondônia. Porto Velho: EMBRAPA. 7p. (Comunicado Técnico, n. 48).

HARTHMANN, O.E.L., JACQUES, A.V.A., TERMIGNONI, R.R. Avaliação agronômica e plantas de capim-elefante (Pennisetum purpureum schum), regeneradas in vitro. Qualidade da forragem. In: REUNIÃO ANUAL DA SOCIEDADE BRASILEIRA DE ZOOTECNIA, 33, Fortaleza, 1996. Anais... Fortaleza: SBZ, 1996. v.2, p.53-55.

JACQUES, A.V.A. 1994. Caracteres morfofisiológicos e suas implicações com o manejo. In: CARVALHO, M.M., ALVIM, M.J., XAVIER, D.F. et al. (Eds.) Capim-elefante, produção e utilização. Coronel Pacheco: EMBRAPA/CNPGL. p.31-48.

LAVEZZO, W., LAVEZZO, O.E.N.M., GARCIA, E.A. Estudo comparativo das variedades Roxo, Mineiro, Vruckwona de capim-elefante (Pennisetum purpureum, Schum.). II - Composição bromatológica pelo método tradicional e análise da fraçãofibrosa.In:REUNIÃO ANUALDA SOCIEDADE BRASILEIRA DE ZOOTECNIA, 22, Balneário Camboriu, 1985. Anais... Balneário Camboriu: SBZ, 1985. p.333.

MINSON, D.J. 1984. Effects of chemical and physical composition of herbage eater upon intake. In: HACKER, J.B (Ed.). Nutritional limits to animal production from pasture. Farnhan Royal, UK. Commonwealth Agriculture Bureaux. p.167-162.

NASCIMENTO JR., D., PINHEIRO, S. 1975. Valor nutritivo do capim-jaraguá em diferentes idades. R. Soc. Bras. Zootec., 4(1):101-113.

NASCIMENTO, I.S. Comportamento produtivo e qualitativo do capim-elefante (Pennisetum purpureum, Schum) cv. Roxo. Areia, PB: UFPB, 1997. 53p. Monografia (Graduação em 
Zootecnia) - Universidade Federal da Paraíba, 1997.

PLUT. D.L., WERNER, J.C. 1967. Efeitos de épocas e de altura de corte sobre o teor de lignina de capim-elefante napier. Bol. Ind. Anim., 24(único):175-84.

QUEIROZ FILHO, J.L., SILVA, D.S., MIRANDA, F.J.M. et al. Valor nutritivo de cultivares de capim-elefante (Pennisetum purpurem, Schum.) no Brejo Paraibano. in: REUNIÃO ANUAL DA SOCIEDADE BRASILEIRA DE ZOOTECNIA, 31, 1994. Anais... Maringá: SBZ, 1994. p.312.

QUEIROZ FILHO, J.L., SILVA, D.S., NASCIMENTO, I.S. et al. 1998. Produção de matéria seca de cultivares e qualidade de cultivares de capim-elefante (Pennisetum purpureum, Schum.). R. Bras. Zootec., 27(2):262-66.

QUEIROZ FILHO, J.L., SILVA, D.S., SILVA, H.O. et al. Efeito do intervalo do primeiro corte sobre a qualidade Capimelefante (Pennisetum purpureum, Schum.) cv. Roxo. In: REUNIÃO ANUAL DA SOCIEDADE BRASILEIRA DE ZOOTECNIA, 34, Juiz de Fora, 1997. Anais... Juiz de Fora: SBZ, 1997. p.213-15.

RODRIGUEZ, N.M., BENEDETTI, E., GONÇALVES, L.C. Avaliação de forrageiras tropicais. II - Conteúdo celular de três diferentes gramíneas no período de janeiro a março de 1992. In: REUNIÃO ANUAL DA SOCIEDADE BRASILEIRA DE ZOOTECNIA, 31, Maringá, 1994. Anais... Maringá: SBZ, 1994. p.270.

RODRIGUEZ, N.M., BENEDETTI, E., GONÇALVES, L.C. Estudo do potencial nutritivo das folhas e caules de três espécies forrageiras. In: REUNIÃO ANUAL DA SOCIEDADE BRASILEIRA DEZOOTECNIA, 31, Maringá, 1994. Anais... Maringá: SBZ, 1994, p.269.

SANTOS, C.J.A. Composição mineral, valor protéico e fatores fisiológicos de 4 cultivares de capim-elefante (Pennisetum purpureum, Schum.), submetidos a duas idades de corte. Recife: UFRPE, 1994. 107p. Dissertação(Mestrado em Produção Animal) - Universidade Federal Rural de Pernambuco, 1994.
SANTOS, E.A., SILVA, D.S., QUEIROZ FILHO. J.L. 2001. Perfilhamento e algumas características morfológicas do capim-elefante cv. Roxo, sob quatro alturas de corte nas duas épocas do ano. Rev. bras. zootec., 30(1):26-32.

SAS - statistical analysis systems. User's guide: Stat, Version 6, 4ed, v.1/2. Cary North Caroline: SAS Institute, 1993.

SILVA, D.J. 1991. Análise de alimentos - métodos químicos e biológicos. Viçosa, MG: UFV. 166p.

SILVEIRA, A.C., TOSI, H., FARIA, V.P. 1974. Efeito da maturidade sobre a composição química bromatológica do capim napier (Pennisetum purpureum, Schum). R. Soc. Bras. Zootec., 3(2):158-171.

VAN SOEST, P.J. 1964. Symposium on nutrition and forage and pasture new chemical procedures for evaluating forages. J. Anim. Sci., 23(3):838-845.

VEIGA, J.B., CAMARÃO, A.P. 1984. Produção forrageira e valor nutritivo de capim-elefante (Pennisetum purpureum, schum) vars. Anão e Cameroon. p.1-6. (EMBRAPA. Comunicado Técnico n. 54)

WERNER, J.C., LIMA F.P., MARTINELLI, D. et al. 1966. Estudos de três diferentes alturas de corte em capim-elefante napier. Bol. Ind. Anim., 23(único):161-168.

WILSON, J.R. 1994. Cell wall characteristics in: relation to forage digestion by ruminants. J. Agric. Sci., 22(2):173.

Recebido em: 15/05/00

Aceito em: 28/09/00 